Article

\title{
Remediation of PAH-Contaminated Soil by Combining Surfactant Enhanced Soil Washing and Iron-Activated Persulfate Oxidation Process
}

\author{
Yanhua Qiu ${ }^{D}$, Meilan Xu, Zongquan Sun and Helian Li * \\ School of Water Conservancy and Environment, University of Jinan, Jinan 250022, China; \\ Qiu_Yan_Hua@163.com (Y.Q.); milan_lyene@163.com (M.X.); sun_zongquan@163.com (Z.S.) \\ * Correspondence: chm_lihl@ujn.edu.cn; Tel.: +86-0531-82769233
}

Received: 19 December 2018; Accepted: 31 January 2019; Published: 2 February 2019

check for updates

\begin{abstract}
There is increasing concern regarding soils contaminated with polycyclic aromatic hydrocarbons (PAHs). In the present study, the remediation of soil spiked with PAHs was explored by the combination of soil washing with sodium dodecyl sulfate (SDS) and subsequent oxidation through persulfate (PS) activated by $\mathrm{Fe}^{2+}$, nanoscale zero-valent iron (nZVI), and $\mathrm{SiO}_{2}$-coated nZVI $\left(\mathrm{SiO}_{2} / \mathrm{nZVI}\right)$. Results demonstrated that the removal of phenanthrene (PHE), fluoranthene (FLU), and pyrene (PYR) by SDS is an efficient means for soil decontamination. At SDS concentration of $20 \mathrm{~g} / \mathrm{L}$, the removal efficiencies of PHE, PYR, and FLU were 37\%, 40\%, and 44\%, respectively. For the degradation of PAHs and SDS in the soil washing effluents, the efficiencies of PS activated with $\mathrm{SiO}_{2} / \mathrm{nZVI}$ were not significantly different from those of PS activated with nZVI and Fe${ }^{2+}(p>0.05)$. In practice, $\mathrm{SiO}_{2} / \mathrm{nZVI}$ is more preferable due to the improved antioxidation and dispersibility. At the dosage of $2 \mathrm{~g} / \mathrm{L}$ (in the amount of iron) of $\mathrm{SiO}_{2} / \mathrm{nZVI}$, the removal efficiencies of PHE, FLU, PYR, and SDS within $30 \mathrm{~min}$ of treatment were $75 \%, 85 \%, 87 \%$, and $34 \%$, respectively. The degradation of SDS was much lower than those of PAHs, which facilitated the recycle of SDS. Our findings suggest that PS activated with $\mathrm{SiO}_{2} / \mathrm{nZVI}$ is a promising method for the treatment of soil washing effluents containing SDS and PAHs.
\end{abstract}

Keywords: soil remediation; PAHs; SDS; SiO2/nZVI; activated persulfate

\section{Introduction}

Polycyclic aromatic hydrocarbons (PAHs) are among the most widespread persistent organic compounds consisting of two or more fused benzene rings. The dominant sources of PAHs in the environment result from the incomplete combustion of organic matter from human activities and natural sources [1]. PAHs are carcinogenic, mutagenic, toxic for reproduction, and can be accumulated by human and other organisms [2,3]. Due to the characteristics of volatile, low solubility, fat solubility, and high octanol-water partition coefficient, PAHs have a tendency to sorb preferably to soil organic matters. Regarding PAHs removal from contaminated soil or groundwater, there is a wide variety of different techniques that can be applied, such as soil washing with surfactants, chemical oxidation $[4,5]$, and biological and thermal treatments [6]. However, the hydrophobic behavior of PAHs can make their remediation using chemical or biological techniques less suitable. The removal of PAHs from soil by soil washing is a preferable method because it is a simple process with low cost and mild operation conditions. Surfactants are usually used in soil washing because they can enhance the solubility of PAHs, decrease the surface tension, and promote the efficiency of soil washing [7]. Among the surfactants, sodium dodecyl sulfate (SDS) is widely used in soil washing of organic pollutants. It consists of a linear hydrocarbon tail attached to a sulfate group that can be easily released into the 
solution. Besides, $\mathrm{SO}_{4}^{2-}$ released by SDS is readily oxidized to $\mathrm{S}_{2} \mathrm{O}_{8}^{2-}$ which in turn can be transformed into $\mathrm{SO}_{4}^{\bullet-}$ by activation (Equation (1)) [8,9].

$$
\mathrm{SO}_{4}^{2-}+\mathrm{SO}_{4}^{2-} \rightarrow \mathrm{S}_{2} \mathrm{O}_{8}^{2-}
$$

However, soil-washing effluents contain a complex mixture of dissolved PAHs and surfactants, which can bring about secondary pollution to the environment if discharged without proper treatment. The methods for the treatment of soil washing wastewater include advanced oxidation process [10], bio-treatment processes [11], electrochemical oxidation [12], photocatalytic processes, and the combination of some of the techniques $[8,13]$.

Compared with other treatment processes, advanced oxidation processes that are based on the production of very reactive radicals $\left(\mathrm{OH} \bullet\right.$ or $\left.\mathrm{SO}_{4}^{\bullet-}\right)$ are one of the highly effective techniques for treatment of soil washing effluents. For decades, sulfate radicals $\left(\mathrm{SO}_{4}^{--}\right)$have been employed to degrade the pollutants in soil and wastewater because of their high redox potential $\left(\mathrm{E}^{0}=2.60 \mathrm{~V}\right)$, which is similar to that of hydroxyl radicals $\left(\mathrm{E}^{0}=2.80 \mathrm{~V}\right)$ [14]. In general, $\mathrm{SO}_{4}^{\bullet-}$ are generated via the activation of persulfate (PS). A variety of activation methods have been researched, including heat, UV-light (Equation (2)), transition metal (Equation (3)), and ultrasound [15].

$$
\begin{gathered}
\mathrm{S}_{2} \mathrm{O}_{8}^{2-}+\text { hv } / \text { heat } \rightarrow 2 \mathrm{SO}_{4}^{\bullet-} \\
\mathrm{S}_{2} \mathrm{O}_{8}^{2-}+\mathrm{M}^{\mathrm{n}+} \rightarrow \mathrm{SO}_{4}^{\bullet-}+\mathrm{SO}_{4}^{2-}+\mathrm{M}^{(\mathrm{n}+1)+}
\end{gathered}
$$

Ferrous, as a transition metal, has better advantages to active persulfate (PS) because it could work at room temperature and under atmospheric pressure. However, there are some limitations, such as the rapid conversion of ferrous $\left(\mathrm{Fe}^{2+}\right)$ into ferric $\left(\mathrm{Fe}^{3+}\right)$ and the scavenging of sulfate radicals by $\mathrm{Fe}^{2+}$, which are described in Equations (4) and (5) [16]. The use of zero-valent iron or nanoscale zero-valent iron (nZVI) has been considered as the source of $\mathrm{Fe}^{2+}$ (Equation (6)) to avoid these problems and to improve the ability to activate PS $[17,18]$. However, there are still some drawbacks to employing nZVI resulting from the gradually reduced reactivity through oxidation in the air. To address this problem, many measures including the surface coating and supporting of nZVI have been adopted to improve the stability and dispersal of nZVI. Many materials have been used to coat nZVI, such as polyacrylic acid [19], biodegradable polymers including guar gum, potato starch, alginic acid, carboxymethyl cellulose [20], and silica [21]. Among these materials, silica $\left(\mathrm{SiO}_{2}\right)$ has better stability, core-shell, and environmental friendliness characteristics [22].

$$
\begin{gathered}
\mathrm{Fe}^{2+}+\mathrm{S}_{2} \mathrm{O}_{8}^{2-} \rightarrow \mathrm{SO}_{4}^{\bullet-}+\mathrm{SO}_{4}^{2-}+\mathrm{Fe}^{3+} \\
\mathrm{Fe}^{2+}+\mathrm{SO}_{4}^{\bullet-} \rightarrow \mathrm{SO}_{4}^{2-}+\mathrm{Fe}^{3+} \\
\mathrm{Fe}^{0}+\mathrm{S}_{2} \mathrm{O}_{8}^{2-} \rightarrow \mathrm{Fe}^{2+}+2 \mathrm{SO}_{4}^{2-}
\end{gathered}
$$

In this study, $\mathrm{nZVI}$ and $\mathrm{SiO}_{2}$-coated $\mathrm{nZVI}\left(\mathrm{SiO}_{2} / \mathrm{nZVI}\right)$ synthesized through a liquid reduction method were employed to active persulfate to produce sulfate radicals for the removal of PAHs and SDS from soil washing effluents. Phenanthrene (PHE), fluoranthene (FLU), and pyrene (PYR) were selected to represent PAHs with different hydrophobicity and molecular size due to the fact that they are frequently detected at high concentrations in soils from industrial contaminated sites. The objectives of this study were to (1) obtain the soil washing efficiencies of PAHs by SDS, (2) assess the removal efficiencies of PAHs and SDS with PS activated by different sources of $\mathrm{Fe}$, including $\mathrm{Fe}^{2+}$, nZVI, and $\mathrm{SiO}_{2} /$ nZVI, and (3) obtain the optimal dosages of $\mathrm{SiO}_{2} /$ nZVI-activated persulfate that should be used in the treatment of soil washing effluents. We propose this as a feasible method for the treatment of washing effluents containing SDS and PAHs in the remediation of contaminated soil. 


\section{Materials and Methods}

\subsection{Reagents}

Phenanthrene (PHE), fluoranthene (FLU), and pyrene (PYR), used for contaminants and HPLC analysis, were purchased from Aladdin Company (Shang Hai, China) with purities of $99 \%, 98 \%$, and $98 \%$, respectively. Analytical grade sodium dodecyl sulfate (SDS) was used as the surfactant. Potassium borohydride $\left(\mathrm{KBH}_{4}\right)$, ferrous sulfate heptahydrate $\left(\mathrm{FeSO}_{4} \cdot 7 \mathrm{H}_{2} \mathrm{O}\right)$, chemical grade polyethylene glycol 4000 (PEG-4000), high-purity nitrogen, and ethanol were used to produce nZVI. Tetraethyl orthosilicate (TEOS) with $98 \%$ purity and sodium hydroxide $(\mathrm{NaOH})$ were both employed to coat nZVI. Sodium persulfate (PS) was applied as the oxidant. For the analysis of SDS, the reagents required were sodium thiosulfate, methylene blue, anhydrous sodium sulfate, and chloroform. All the reagents were obtained from Sinopharm Chemical Reagent Co., Ltd (Shang Hai, China) unless otherwise noted.

\subsection{Soil Spiking and Soil Washing}

The soil used in this work was collected from a suburb of Jinan, China. The main soil properties were previously determined by Li et al. [23] and are given in Table 1. The spiked soil was prepared following the method of Zhou and Zhu [24]. Briefly, a methanol solution with PHE, FLU, and PYR was distributed and mixed manually into the soil with a spatula. Then, the solvent was allowed to evaporate slowly in a fume hood. The final concentration of PHE, FLU, and PYR was $100 \mathrm{mg} / \mathrm{kg}$ for each, which represented the PAH concentration level of industrial contaminated sites.

Table 1. Main properties of the soil.

\begin{tabular}{cc}
\hline Property & Value \\
\hline Sand (\%) & 53 \\
Silt (\%) & 24 \\
Clay (\%) & 22 \\
pH & 6.8 \\
Organic carbon $(\%)$ & 0.8 \\
Cation exchange capacity $\left(\mathrm{cmol} \cdot \mathrm{kg}^{-1}\right)$ & 6.8 \\
\hline
\end{tabular}

To obtain the PAH removal efficiencies by SDS in the soil washing process, twenty grams of polluted soil were placed in 1-L Erlenmeyer flasks. Then, $200 \mathrm{~mL}$ of SDS solutions at different concentrations was added to each flask. The flasks were put on a reciprocating shaker $(200 \mathrm{rpm}$, $25 \pm 1{ }^{\circ} \mathrm{C}$ ) for $48 \mathrm{~h}$. After that, the suspensions were centrifuged, and a specific volume of the supernatant was collected to determine the PAH concentrations.

\subsection{Synthesis and Characterization of $n \mathrm{ZVI}$ and $\mathrm{SiO}_{2} / n \mathrm{ZVI}$}

nZVI was synthesized through the liquid reduction method using $\mathrm{KBH}_{4}$ to reduce $\mathrm{Fe}^{2+}$. A quantity of $2.78 \mathrm{~g}$ of $\mathrm{FeSO}_{4} \cdot 7 \mathrm{H}_{2} \mathrm{O}$ dissolved in $100 \mathrm{~mL}$ ethanol $/ \mathrm{H}_{2} \mathrm{O}(v / v=7: 3)$ solution, and $0.5 \mathrm{~g}$ of PEG-4000, as the dispersant, were added into a $500-\mathrm{mL}$ three-neck flask. Iron nanoparticles produced were stirred for $30 \mathrm{~min}$ while $30 \mathrm{~mL}$ of $1 \mathrm{~mol} \cdot \mathrm{L}^{-1} \mathrm{KBH}_{4}$ was dropped into the three-neck flasks at a rate of 2 drops/sec under nitrogen. The synthetic process of $\mathrm{SiO}_{2} / \mathrm{nZVI}$ was similar to previous work [25], with silicon alkoxide as a silica source and amine as a catalyst. A volume of $20 \mathrm{~mL}$ of $5 \mathrm{~mol} / \mathrm{L}$ $\mathrm{NaOH}$ and $5 \mathrm{~mL}$ TEOS were added to the iron nanoparticle solution then stirred for $1 \mathrm{~h}$. After the reaction, the products were cleaned by deoxygenated water and ethanol three times and dried through vacuum freeze-drying.

The surface morphologies of $\mathrm{nZVI}$ and $\mathrm{SiO}_{2} / \mathrm{nZVI}$ were analyzed using a Nova 450 scanning electron microscope (SEM, USA) at an acceleration voltage of $10 \mathrm{kV}$. The crystal structures of nZVI and $\mathrm{SiO}_{2} / \mathrm{nZVI}$ were characterized by X-ray diffractometer (XRD, Ultima IV, Japan) with $\mathrm{Cu} \mathrm{K} \alpha$ radiation $(\lambda=1.5408 \mathrm{~nm})$. 


\subsection{PAHs Degradation in Soil Washing Effluents}

Batch experiments were conducted with soil washing effluents without $\mathrm{pH}$ adjustment by using $100 \mathrm{~mL}$ Erlenmeyer flasks as reactors equilibrated on a reciprocating shaker at $25 \pm 1{ }^{\circ} \mathrm{C}$. Fifty milliliters of soil washing effluents were treated with $10 \mathrm{~mL}$ of PS solution $(50 \mathrm{mM})$ containing $\mathrm{FeSO}_{4}, \mathrm{nZVI}$, or $\mathrm{SiO}_{2} / \mathrm{nZVI}$ synthesized in the same batch. At regular time intervals, a volume of $2 \mathrm{~mL}$ sample was removed and filtered through a $0.45 \mu \mathrm{m}$ PTFE syringe filter. After filtration, $0.020 \mathrm{~mol} \cdot \mathrm{L}^{-1} \mathrm{NaS}_{2} \mathrm{O}_{3}$ solution (much more than PS) was added to halt the reaction. All these experiments were performed in duplicate.

\subsection{Analytical Method}

The concentration of SDS was measured following the methylene blue method with a UV-visible spectrophotometer (Shimadzu, Japan) at a wavelength of $650 \mathrm{~nm}$ [26]. The concentrations of PAHs were determined by HPLC (Ultimate-3000, Dionex, Sunnyvale, CA, USA) using an ultraviolet detector at a wavelength of $251 \mathrm{~nm}$. The analytical column was a reversed phase SUPELCOSIL LC-PAH column $(150 \times 4.6 \mathrm{~mm}, 5 \mu \mathrm{m})$. The mobile phase was $90 \%$ methanol and $10 \%$ deionized water eluted at a flow rate of $1.0 \mathrm{~mL} \cdot \mathrm{min}^{-1}$. The degradation efficiency of each PAH and SDS was calculated by Equation (7).

$$
\text { Degradation efficiency }(\%)=\frac{C_{0}-C_{e}}{C_{0}} \times 100
$$

$C_{0}$ is the initial concentration of PAHs or SDS, and $C_{e}$ is the concentration of PAHs or SDS at equilibrium.

\subsection{Statistical Analysis}

Statistical analysis was performed using SPSS 22.0 (SPSS Inc. Chicago, IL, USA) software. One-way ANOVA followed by the least significant difference (LSD) test was used to compare the difference among different treatments. Statistical significance was accepted at $p<0.05$.

\section{Results and Discussion}

\subsection{The Characterization of $n \mathrm{ZVI}$ and $\mathrm{SiO}_{2} / n \mathrm{ZVI}$}

The representative SEM images of nZVI and $\mathrm{SiO}_{2} /$ nZVI are shown in Figure 1a,b. As can be seen, the shape of synthesized $\mathrm{nZVI}$ and $\mathrm{SiO}_{2} / \mathrm{nZVI}$ particles was spherical with the particle size range in the nanoscale. The morphology of nZVI also showed that nZVI formed as chain-like aggregates due to magnetic interaction between small particles. $\mathrm{SiO}_{2} / \mathrm{nZVI}$ has much better dispersion performance than nZVI, suggesting that the coating of $\mathrm{SiO}_{2}$ can prevent aggregation by reducing the Van der Waals force and magnetic force between iron nanoparticles. The XRD patterns of the synthesized materials are shown in Figure 1c. From the XRD patterns of nZVI and $\mathrm{SiO}_{2} / \mathrm{nZVI}$, the diffraction peak at $2 \theta=45^{\circ}$ confirms the existence of zero-valent iron $(\alpha-\mathrm{Fe})$.

\subsection{The Washing Efficiencies of PAHs}

In order to assess the removal efficiencies of PAHs from the contaminated soil, soil washing experiments were performed with soils containing PHE, FLU, and PYR at different SDS concentrations. It was not so effective to transfer PAHs from the soil to the liquid phase at low concentrations of SDS (Figure 2). This may be due to the adsorption and precipitation of SDS in the soil-water system, which increased the concentration of SDS required to form micelles that can greatly solubilize PAHs [27]. The removal efficiencies for PHE, FLU, and PYR increased with increasing the concentration of SDS. At a concentration of $20 \mathrm{~g} / \mathrm{L}$ of SDS, the removal efficiencies of PHE, FLU, and PYR were $37 \%, 40 \%$, and $44 \%$, respectively. Significant loss of SDS occurred during soil washing process due to the reaction of the cations $\left(\mathrm{Mg}^{2+}\right.$ and $\left.\mathrm{Ca}^{2+}\right)$ and the sulfate of SDS [27]. In addition, the soil washing effluent was 
composed of low concentrations of PAHs and a much higher concentration of SDS. The concentration of PHE, FLU, PYR, and SDS in the washing effluents were $3.8 \mathrm{mg} / \mathrm{L}, 4.0 \mathrm{mg} / \mathrm{L}, 4.8 \mathrm{mg} / \mathrm{L}$, and $16 \mathrm{mg} / \mathrm{L}$, respectively. Therefore, the pollution of soil washing effluent was concerned with the high organic load associated with SDS, although the toxicity is mainly owing to the existence of the PAHs rather than SDS.

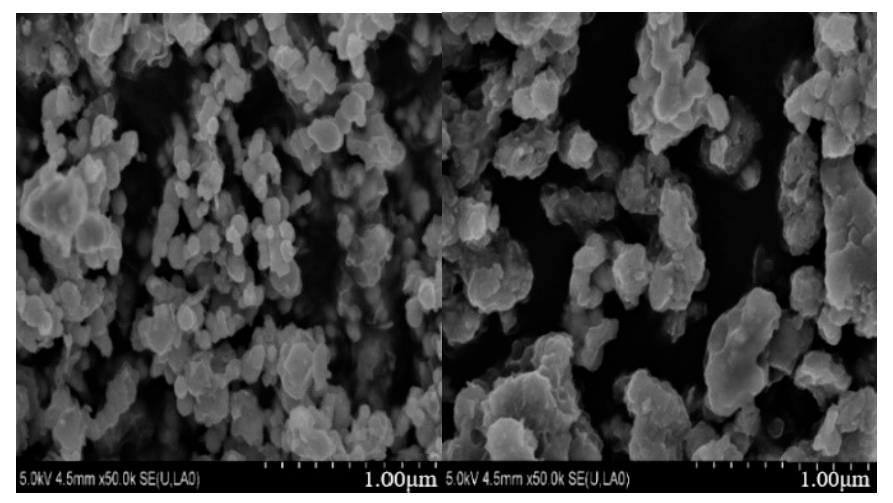

(a)

(b)

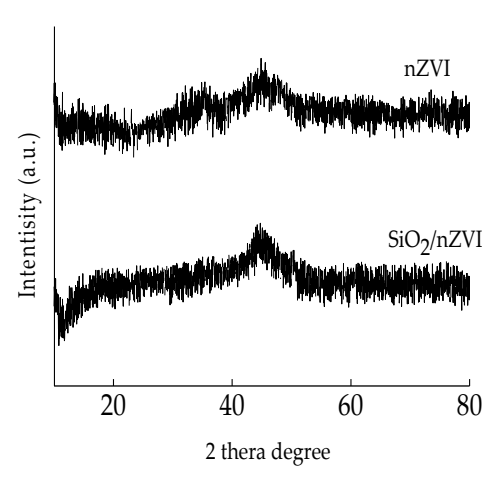

(c)

Figure 1. Scanning electron microscope (SEM) images of (a) nanoscale zero-valent iron (nZVI), (b) $\mathrm{SiO}_{2}$-coated nZVI $\left(\mathrm{SiO}_{2} / \mathrm{nZVI}\right.$ ), and (c) X-ray diffraction (XRD) patterns of nZVI and $\mathrm{SiO}_{2} / \mathrm{nZVI}$.

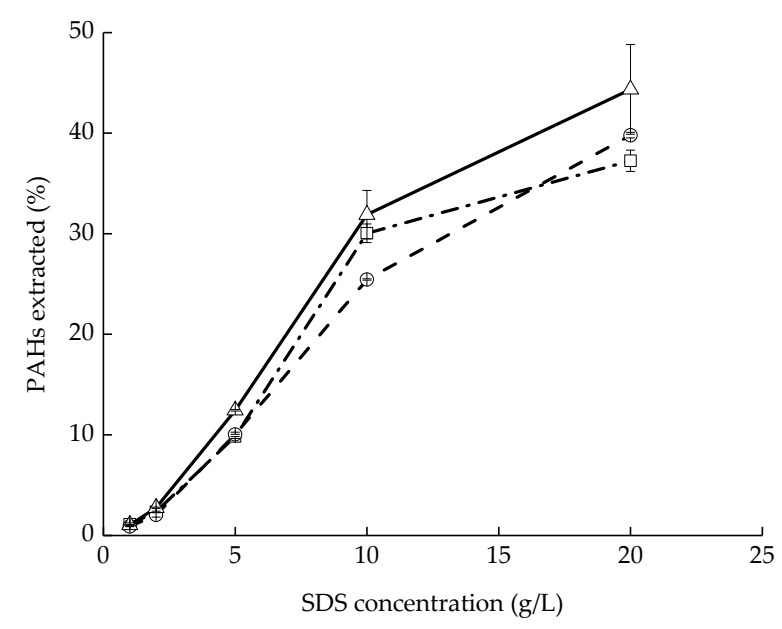

Figure 2. The washing efficiencies of (--- $\square---)$ phenanthrene (PHE), (- - - - -) fluoranthene (FLU), and $(-\triangle-)$ pyrene (PYR) at different concentrations of sodium dodecyl sulfate (SDS). Values are presented as means and standard deviation.

In soil washing processes, the removal efficiencies of organic contaminants depend on the characteristics of the specific soil-surfactant system, such as the initial levels of pollutants, the soil properties, and the aging time of pollutants. It was reported that the removal efficiency increased with increasing the initial concentration of organic contaminants due to the increased contact area between the surfactant and the contaminant [28]. Soil properties have an important effect on the removal of PAHs by washing. Zhou and Zhu [24] showed the removal of PAHs was easier in soil with relatively low organic carbon and clay contents. Moreover, longer aging time resulted in decreased removal efficiencies of soil washing.

\subsection{Effect of the DegradationTime}

Figure 3 describes the degradation efficiencies of PAHs and SDS by iron-activated PS with time. As can be seen, for the PS activated by $2 \mathrm{~g} / \mathrm{L}$ (in the amount of iron) of $\mathrm{SiO}_{2} / \mathrm{nZVI}, \mathrm{nZVI}$, and $\mathrm{Fe}^{2+}$, the degradation rates of PAHs increased rapidly at the beginning of the experiment, with more than $60 \%$ removal occurring in the initial $10 \mathrm{~min}$. It indicated that $\mathrm{S}_{2} \mathrm{O}_{8}^{2-}$ can be activated to generate a 
large amount of $\mathrm{SO}_{4}^{\bullet-}$ in a short time. After that, the degradation proceeded much slower, reaching equilibrium at $30 \mathrm{~min}$. The change from the initial fast degradation rate to slower one was possibly caused by the aggregation as well as the surface passivation of nanoparticles [22,29].

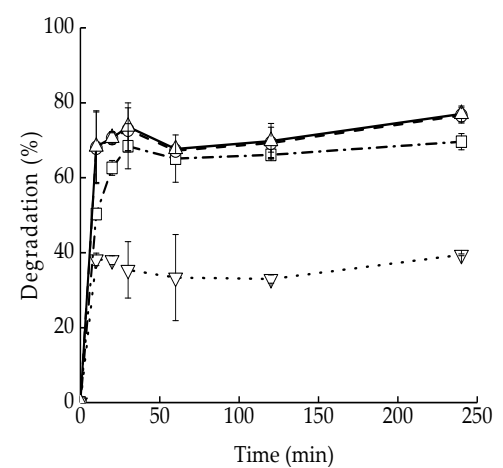

(a)

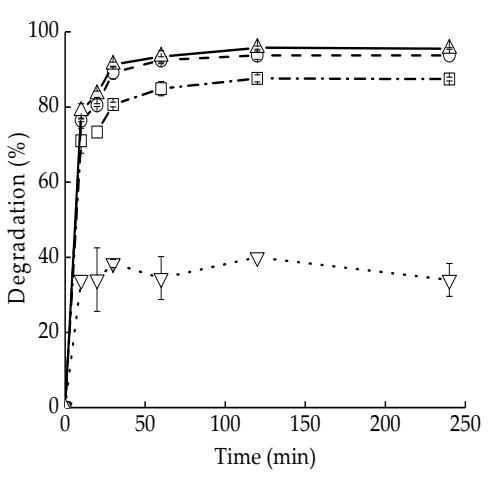

(b)

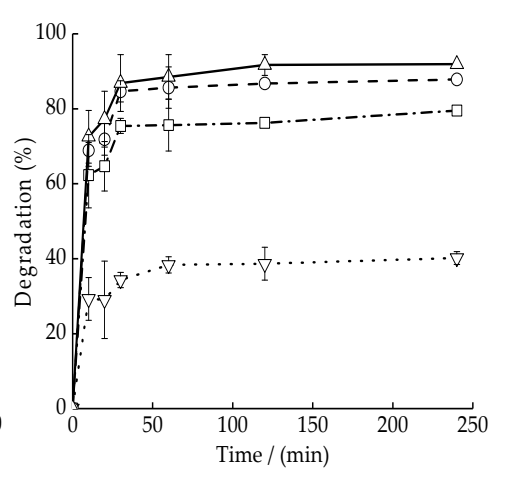

(c)

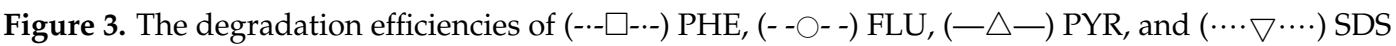
by (a) $\mathrm{Fe}^{2+}$, (b) nZVI, and (c) $\mathrm{SiO}_{2} /$ nZVI activated persulfate (PS) with time. Values are presented as means and standard deviation.

\subsection{Effect of the Source of Iron}

As it was previously cited, iron was added as $\mathrm{Fe}^{2+}, \mathrm{nZVI}$, or $\mathrm{SiO}_{2} / \mathrm{nZVI}$. Figure 4 shows the degradation efficiencies of PHE, FLU, PYR, and SDS in soil washing effluents by activated PS. The degradation efficiencies of PAHs were higher for nZVI activation than $\mathrm{Fe}^{2+}$ activation, with a final degradation of PHE, FLU, and PYR of $84 \%, 89 \%$, and $91 \%$, respectively. This could be explained by the fact that nZVI produce a slower release of iron, minimizing the radical scavenger in Equation (5). Similar results were reported for the removal of PAHs and trichloroethylene with PS activated by $\mathrm{Fe}^{2+}[30,31]$. In the case of $\mathrm{SiO}_{2} / \mathrm{nZVI}$, the degradation efficiencies of PHE, FLU, and PYR were 75\%, $85 \%$, and $87 \%$, respectively, which were not significantly different from those of nZVI system. There are contradictory results in the literature. According to Wan et al. [32], $\mathrm{SiO}_{2} / \mathrm{nZVI}$ showed an improvement of about $35 \%$ removal of 2,4-dichlorophenol compared to nZVI. However, no improvement in the PAH removal by $\mathrm{SiO}_{2} / \mathrm{nZVI}$ was observed in our study. The oxidation and agglomeration of nZVI can be well-suppressed by coating with $\mathrm{SiO}_{2}$, although the $\mathrm{PAH}$ removal efficiencies were not improved. Moreover, it is noted that the degradation efficiencies of FLU and PYR, with a ring number of 4, are higher than PHE, with a ring number of 3 , which is consistent with the findings of Peluffo et al. [30]. It might be explained by the higher availability of PAHs with a higher ring number in freshly spiked soils and the reduced energy required to form the oxidation products $[30,33]$. It should be noted that there would be some difference in the degradation efficiency for soil effluents with different initial pollutant levels. Wei et al. [34] showed that the degradation efficiency increased with increasing initial contaminant concentration, but there was an optimal concentration at which the maximum removal efficiency could be obtained.

As for SDS, no significant difference was observed in the degradation efficiencies by PS activated with different sources of irons. The degradation efficiency of SDS was 34-38\%, which is much lower than those of PAHs. The high residual of SDS makes it possible for the reuse of the treated effluent for subsequent washing processes. Similar results were reported in the treatment of soil washing effluents containing other organic pollutants and sulfates by activated PS. According to Tsitonaki et al. [35] and Long et al. [36], $\mathrm{SO}_{4}^{\cdot-}$ may oxidize benzene toluene ethylbenzene and xylene with a faster reaction rate than straight chain hydrocarbon surfactants that do not contain a benzene ring, so that SDS can be recycled from the soil washing water. In the mixture solution of nitrobenzene (NB) and sodium dodecyl benzene sulfonate (SDBS), the generated $\mathrm{SO}_{4}^{--}$exhibited preferential degradation of $\mathrm{NB}$ by electron transfer over SDBS through hydrogen abstraction reactions [37]. 


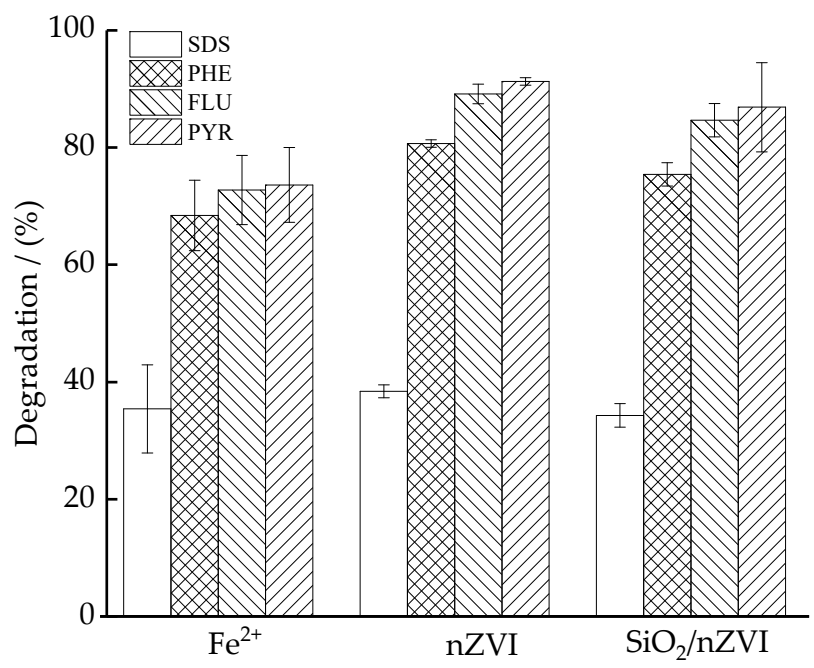

Figure 4. The degradation of PAHs and SDS in soil washing effluents with PS activated by different sources of iron $\left(\mathrm{Fe}^{2+}, \mathrm{nZVI}\right.$, and $\left.\mathrm{SiO}_{2} / \mathrm{nZVI}\right)$. Values are presented as means and standard deviation.

\subsection{Effect of the Dosage of $\mathrm{SiO}_{2} / \mathrm{nZVI}$}

Figure 5 shows the degradation efficiencies of PAHs and SDS in soil washing effluents with PS activated by different dosages of $\mathrm{SiO}_{2} / \mathrm{nZVI}$. For PHE, FLU, PYR, and SDS, the removal efficiencies were the highest at $2 \mathrm{~g} / \mathrm{L}$ of $\mathrm{SiO}_{2} / \mathrm{nZVI}$ at equilibrium. It can be explained that more $\mathrm{Fe}^{2+}$ were released with increasing $\mathrm{SiO}_{2} / \mathrm{nZVI}$, which facilitated the decomposition of $\mathrm{PS}$ to generate more $\mathrm{SO}_{4}^{\bullet-}$ (Equation (4)). Meanwhile, $\mathrm{SiO}_{2} / \mathrm{nZVI}$ can remove pollutants by itself. According to Wan et al. [32], $\mathrm{SiO}_{2}$ adsorption contributed $10 \%$ removal of 2,4-dichlorophenol. Nevertheless, the degradation of PAHs decreased when the dosage increased to $4 \mathrm{~g} / \mathrm{L}$. It can be inferred that the higher the dosage of $\mathrm{SiO}_{2} / \mathrm{nZVI}$, the higher the PS consumption, which produced more sulfate radicals resulting in scavenging reactions (Equation (8)). In addition, $\mathrm{PS}$ and excess $\mathrm{Fe}^{2+}$ released from $\mathrm{SiO}_{2} / \mathrm{nZVI}$ (Equation (6)) could scavenge sulfate radicals (Equations (5) and (9)). The higher concentrations of $\mathrm{SiO}_{2} / \mathrm{nZVI}$ also made it easier to agglomerate with each other which may decrease the ability to activate PS.

$$
\begin{gathered}
2 \mathrm{SO}_{4}^{\bullet-} \rightarrow \mathrm{S}_{2} \mathrm{O}_{8}^{2-} \\
\mathrm{SO}_{4}^{\bullet-}+\mathrm{S}_{2} \mathrm{O}_{8}^{2-} \rightarrow 3 \mathrm{SO}_{4}^{2-}
\end{gathered}
$$

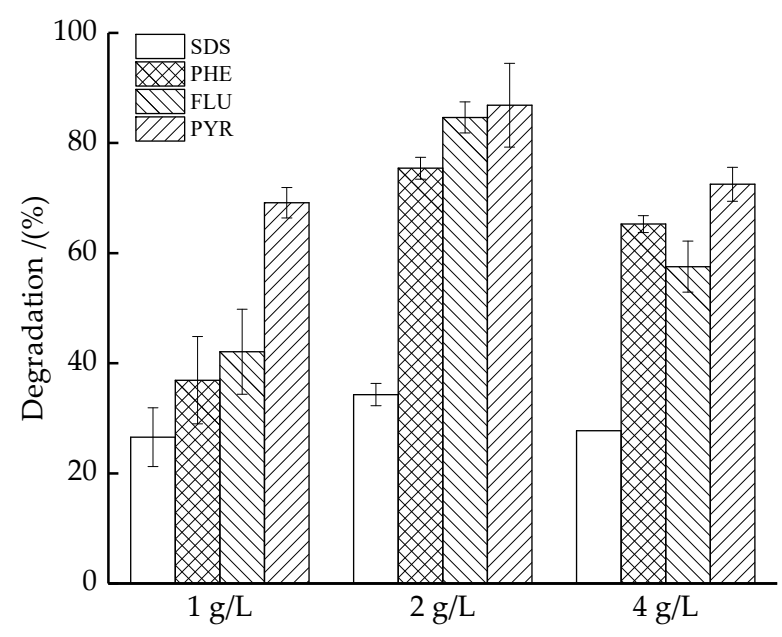

Figure 5. The degradation of PAHs and SDS in soil washing effluents by PS activated with different dosage of $\mathrm{SiO}_{2} / \mathrm{nZVI}(1,2$, and $4 \mathrm{~g} / \mathrm{L})$. Values are presented as means and standard deviation. 


\section{Limitations}

In this study, PHE, FLU, and PYR were selected to represent PAHs with different hydrophobicity and molecular size. However, the three PAHs are not completely representative of the behavior of all PAHs as a whole due to the difference in physicochemical properties. There would be some difference in the washing efficiencies and cleanup of the breakdown products if higher molecular weight PAHs had been used, which needs to be studied further in the future.

Aging time has a major effect on the removal of PAHs by soil washing. Longer aging times are likely to be more representative of real-world contaminated soils. However, freshly spiked soil was used in this paper which mainly focused on the treatments of soil washing effluents.

In this study, nZVI synthesized in a single batch was used for the degradation experiments. However, batch to batch reproducibility of experimental results can be quite poor for nanomaterials. Batch-to-batch reproducibility of the results was not tested, which is also a limitation of the study.

In spite of the above limitations of the study, this paper provides important information for the treatment of soil washing effluents containing SDS and PAHs.

\section{Conclusions}

PAHs can be effectively removed from the soil by soil washing using SDS as the surfactant. The removal efficiencies of PAHs were 37-44\% at an SDS concentration of $20 \mathrm{~g} / \mathrm{L}$. PS activated by different sources of iron $\left(\mathrm{Fe}^{2+}, \mathrm{nZVI}\right.$, and $\left.\mathrm{SiO}_{2} / \mathrm{nZVI}\right)$ can effectively degrade PAHs in soil washing effluents. Among the three sources of iron, $\mathrm{SiO}_{2} / \mathrm{nZVI}$ had a comparable ability to nZVI in the degradation of PAHs and SDS. The oxidation and agglomeration of nZVI can be well-suppressed by coating with $\mathrm{SiO}_{2}$, which makes it more preferable in practice. At the dosage of $2 \mathrm{~g} / \mathrm{L}$ (in the amount of iron) of $\mathrm{SiO}_{2} / \mathrm{nZVI}$, the removal efficiencies of PHE, FLU, PYR, and SDS within 30 min of treatment were $75 \%, 85 \%, 87 \%$, and 34\%, respectively. Moreover, the degradation of SDS was much lower than those of PAHs in soil washing effluents, which facilitated the recycling of SDS. It is suggested that the combination of soil washing with SDS and iron-activated persulfate oxidation is a feasible route in the remediation of PAH-contaminated soil.

Author Contributions: Y.Q. and Z.S. performed the experiments and prepared the original draft; M.X., Y.Q., and H.L. conceptualized the study and analyzed the data; H.L. reviewed and edited the final manuscript.

Funding: This research was funded by the National Natural Science Foundation of China (41771524).

Conflicts of Interest: The authors declare no conflict of interest.

\section{References}

1. Gan, S.; Lau, E.V.; Ng, H.K. Remediation of soils contaminated with polycyclic aromatic hydrocarbons (PAHs). J. Hazard. Mater. 2009, 172, 532-549. [CrossRef] [PubMed]

2. Johnson, N.M.; Afriyie-Gyawu, E.; Huebner, H.; Marroquin-Cardona, A.; Robinson, A.; Tang, L.; Xu, L.; Ankrah, N.A.; Ofori-Adjei, D.; Jolly, P.E.; et al. PAH exposure in a Ghanaian population at high risk for aflatoxicosis. Sci. Total Environ. 2009, 407, 1886-1891. [CrossRef] [PubMed]

3. Bansal, V.; Kim, K.H. Review of PAH contamination in food products and their health hazards. Environ. Int. 2015, 84, 26-38. [CrossRef] [PubMed]

4. Flotron, V.; Delteil, C.; Padellec, Y.; Camel, V. Removal of sorbed polycyclic aromatic hydrocarbons from soil, sludge and sediment samples using the Fenton's reagent process. Chemosphere 2005, 59, 1427-1437. [CrossRef] [PubMed]

5. O'Mahony, M.M.; Dobson, A.D.W.; Barnes, J.D.; Singleton, I. The use of ozone in the remediation of polycyclic aromatic hydrocarbon contaminated soil. Chemosphere 2006, 63, 307-314. [CrossRef] [PubMed]

6. Cai, Q.Y.; Mo, C.H.; Wu, Q.T.; Zeng, Q.Y.; Katsoyiannis, A.; Férard, J.F. Bioremediation of polycyclic aromatic hydrocarbons (PAHs)-contaminated sewage sludge by different composting processes. J. Hazard. Mater. 2007, 142, 535-542. [CrossRef] [PubMed] 
7. Seo, Y.; Bishop, P.L. Influence of nonionic surfactant on attached biofilm formation and phenanthrene bioavailability during simulated surfactant enhanced bioremediation. Environ. Sci. Technol. 2007, 41, 7107-7113. [CrossRef] [PubMed]

8. Chair, K.; Bedoui, A.; Bensalah, N.; Fernández-Morales, F.J.; Sáez, C.; Cañizares, P.; Rodrigo, M.A. Combining bioadsorption and photoelectrochemical oxidation for the treatment of soil-washing effluents polluted with herbicide 2,4-D. J. Chem. Technol. Biot. 2016, 92, 83-89. [CrossRef]

9. Chair, K.; Bedoui, A.; Bensalah, N.; Sáez, C.; Fernández-Morales, F.J.; Cotillas, S.; Cañizares, P.; Rodrigo, M.A. Treatment of soil-washing effluents polluted with herbicide oxyfluorfen by combined biosorption-electrolysis. Ind. Eng. Chem. Res. 2017, 56, 1903-1910. [CrossRef]

10. Trellu, C.; Mousset, E.; Pechaud, Y.; Huguenot, D.; van Hullebusch, E.D.; Esposito, G.; Oturan, M.A. Removal of hydrophobic organic pollutants from soil washing/flushing solutions: A critical review. J. Hazard. Mater. 2016, 306, 149-174. [CrossRef]

11. Maza-Márquez, P.; Martinez-Toledo, M.V.; Fenice, M.; Andrade, L.; Lasserrot, A. Gonzalez-Lopez, Biotreatment of olive washing wastewater by a selected microalgal-bacterial consortium. Int. Biodeter. Biodeger. 2014, 88, 69-76. [CrossRef]

12. Lopez-Vizcaíno, R.; Sáez, C.; Cañizares, P.; Rodrigo, M.A. Electrocoagulation of the effluents from surfactant-aided soil-remediation processes. Sep. Purif. Technol. 2012, 98, 88-93. [CrossRef]

13. Fabbri, D.; Crime, A.; Davezza, M.; Medana, C.; Baiocchi, C.; Prevot, A.B.; Pramauro, E. Surfactant-assisted removal of swep residues from soil and photocatalytic treatment of the washing wastes. Appl. Catal. B-Environ. 2009, 92, 318-325. [CrossRef]

14. Pardo, F.; Rosas, J.M.; Santos, A.; Romero, A. Remediation of a biodiesel blend-contaminated soil with activated persulfate by different sources of iron. Water Air Soil Pollut. 2015, 226, 17. [CrossRef]

15. Matzek, L.W.; Carter, K.E. Activated persulfate for organic chemical degradation: A review. Chemosphere 2016, 151, 178-188. [CrossRef] [PubMed]

16. Yan, D.Y.S.; Lo, I.M.C. Removal effectiveness and mechanisms of naphthalene and heavy metals from artificially contaminated soil by iron chelate-activated persulfate. Environ. Pollut. 2013, 178, 15-22. [CrossRef]

17. Kang, Y.G.; Yoon, H.; Lee, W.; Kim, E.j.; Chang, Y.S. Comparative study of peroxide oxidants activated by nZVI: Removal of 1,4-Dioxane and arsenic (III) in contaminated waters. Chem. Eng. J. 2018, 334, 2511-2519. [CrossRef]

18. Liang, C.; Lai, M.C. Trichloroethylene degradation by zero valent iron activated persulfate oxidation. Environ. Eng. Sci. 2008, 25, 1071-1078. [CrossRef]

19. Kim, H.S.; Ahn, J.Y.; Kim, C.; Lee, S.; Hwang, I. Effect of anions and humic acid on the performance of nanoscale zero-valent iron particles coated with polyacrylic acid. Chemosphere 2014, 113, 93-100. [CrossRef]

20. Xiao, R.; Wazne, M. Assessment of aged biodegradable polymer-coated nano-zero-valent iron for degradation of hexahydro-1,3,5-trinitro-1,3,5-triazine (RDX). J. Chem. Technol. Biot. 2012, 88, 711-718. [CrossRef]

21. Peng, Z.; Xiong, C.; Wang, W.; Tan, F.; Xu, Y.; Wang, X.; Qiao, X. Facile modification of nanoscale zero-valent iron with high stability for Cr(VI) remediation. Sci. Total Environ. 2017, 596-597, 266-273. [CrossRef] [PubMed]

22. Wang, Y.; Chen, S.y.; Yang, X.; Huang, X.F.; Yang, Y.H.; He, E.K.; Wang, S.; Qiu, R.L. Degradation of 2,2',4,4'-tetrabromodiphenyl ether (BDE-47) by a nano zerovalent iron-activated persulfate process: The effect of metal ions. Chem. Eng. J. 2017, 317, 613-622. [CrossRef]

23. Li, H.; Qu, R.; Li, C.; Guo, W.; Han, X.; He, F.; Ma, Y.B.; Xing, B.S. Selective removal of polycyclic aromatic hydrocarbons (PAHs) from soil washing effluents using biochars produced at different pyrolytic temperatures. Bioresour. Technol. 2014, 163, 193-198. [CrossRef] [PubMed]

24. Zhou, W.; Zhu, L. Efficiency of surfactant-enhanced desorption for contaminated soils depending on the component characteristics of soil-surfactant-PAHs system. Environ. Pollut. 2007, 147, 66-73. [CrossRef] [PubMed]

25. Li, Y.; Jin, Z.; Li, T.; Xiu, Z. One-step synthesis and characterization of core-shell Fe@SiO 2 nanocomposite for Cr (VI) reduction. Sci. Total Environ. 2012, 421-422, 260-266. [CrossRef] [PubMed]

26. Jurado, E.; Fernández-Serrano, M.; Núñez-Olea, J.; Luzón, G.; Lechuga, M. Simplified spectrophotometric method using methylene blue for determining anionic surfactants: Applications to the study of primary biodegradation in aerobic screening tests. Chemosphere 2006, 65, 278-285. [CrossRef] [PubMed] 
27. Li, H.; Qu, R.; Han, X.; Chen, J. Surfactant-enhanced washing of aged PAH-contaminated soils: comparison between nonionic surfactant and anionic surfactant. Appl. Mech. Mater. 2014, 522-524, 316-321. [CrossRef]

28. Befkadu, A.A.; Chen, Q. Surfactant-Enhanced Soil Washing for Removal of Petroleum Hydrocarbons from Contaminated Soils: A Review. Pedosphere 2018, 28, 383-410. [CrossRef]

29. Dong, H.; He, Q.; Zeng, G.; Tang, L.; Zhang, L.; Xie, Y.; Zeng, Y.; Zhao, F. Degradation of trichloroethene by nanoscale zero-valent iron (nZVI) and nZVI activated persulfate in the absence and presence of EDTA. Chem. Eng. J. 2017, 316, 410-418. [CrossRef]

30. Peluffo, M.; Pardo, F.; Santos, A.; Romero, A. Use of different kinds of persulfate activation with iron for the remediation of a PAH-contaminated soil. Sci. Total Environ. 2016, 563-564, 649-656. [CrossRef]

31. Al-Shamsi, M.A.; Thomson, N.R. Treatment of organic compounds by activated persulfate using nanoscale zero valent iron. Ind. Eng. Chem. Res. 2013, 52, 13564-13571. [CrossRef]

32. Wan, J.; Wan, J.; Ma, Y.; Huang, M.; Wang, Y.; Ren, R. Reactivity characteristics of $\mathrm{SiO}_{2}$-coated zero-valent iron nanoparticles for 2,4-dichlorophenol degradation. Chem. Eng. J. 2013, 221, 300-307. [CrossRef]

33. Forsey, S.P.; Thomson, N.R.; Barker, J.F. Oxidation kinetics of polycyclic aromatic hydrocarbons by permanganate. Chemosphere 2010, 79, 628-636. [CrossRef] [PubMed]

34. Wei, X.; Gao, N.; Li, C.; Yang, D.; Zhou, S.; Lei, L. Zero-valent iron (ZVI) activation of persulfate (PS) for oxidation of bentazon in water. Chem. Eng. J. 2016, 285, 660-670. [CrossRef]

35. Tsitonaki, A.; Petri, B.; Crimi, M.; MosbÆK, H.; Siegrist, R.L.; Bjerg, P.L. In situ chemical oxidation of contaminated soil and groundwater using persulfate: A review. Crit. Rev. Environ. Sci. Technol. 2010, 40, 55-91. [CrossRef]

36. Long, A.; Zhang, H.; Lei, Y. Surfactant flushing remediation of toluene-contaminated soil: optimization with response surface methodology and surfactant recovery by selective oxidation with sulfate radicals. Sep. Purif. Technol. 2013, 118, 612-619. [CrossRef]

37. Yan, J.; Gao, W.; Qian, L.; Han, L.; Chen, Y.; Chen, M. Remediation of nitrobenzene contaminated soil by combining surfactant enhanced soil washing and effluent oxidation with persulfate. PLoS ONE 2015, 10, e0132878. [CrossRef] 